\title{
EDITORIAL
}

\section{Strength and weakness of the new TNM classification for lung cancer}

\author{
R. Rami-Porta* and P. Goldstraw ${ }^{\#}$
}

$\mathbf{T}$ he article by STRAND et al. [1] on the evaluation of the new tumour, node, metastasis (TNM) classification and staging system for lung cancer raises important questions on the validity of the classification and its therapeutic implications in clinical practice. The authors analysed a population-based series of 1,885 patients who underwent operation for lung cancer and who were registered at the Cancer Registry of Norway from 2001 to 2005. They pathologically classified these tumours according to the 6th [2] and 7th [3] editions of the TNM classification to assess their prognostic capacity, and found that the 7 th edition did not improve the overall predictive ability of the staging system. Moreover, based on the current indications of therapy, nearly one-fifth of the patients could be offered different treatment options because of the rearrangement of some TNM subsets in different stages. Whether this different treatment will result in an improved prognosis is unknown.

Regarding the prognostic capacity of the 7th edition of the TNM classification, the authors' results contradict those of the International Association for the Study of Lung Cancer (IASLC), whose database of $>100,000$ patients collected worldwide was used to revise the 6th edition of the classification [4], and those of others whose patient series have validated most of the changes introduced in the 7th edition. Soon after the publication of the recommended changes for the new edition, independent groups validated them based on their own data or on data from registries. ZeLL et al. [5] and OU and ZELL [6, 7] found that the proposed changes better reflected survival for advanced bronchioloalveolar carcinoma and for small cell lung cancer, and validated the revisions of the T4 and M descriptors, respectively. OliARO et al. [8], LEE et al. [9] and FiLOsso et al. [10] found that the reclassification of additional tumour nodules allows better prognostication. Additionally, LEE et al. [11], and FUKUI et al. [12] validated the prognostic impact of the extent of nodal involvement, and the overall validity of the new TNM classification, respectively. After the publication of the 7th edition of the TNM classification, SUZUKI et al. [13], RUFFINI et al. [14] and YANO et al. [15] have validated most of the changes incorporated into this new edition, highlighting its superiority compared with the previous one.

*Thoracic Surgery Service, Hospital Universitari Mútua Terrassa, Terrassa, Barcelona, Spain. ${ }^{\text {\#Dept }}$ of Thoracic Surgery, Royal Brompton Hospital and Imperial College, London, UK.

CORRESPONDENCE: R. Rami-Porta, Thoracic Surgery Service, Hospital Universitari Mútua Terrassa, Plaza Dr. Robert 5, 08221 Terrassa, Barcelona, Spain. E-mail: rramip@terra.es
As STRAND et al. [1] point out, the external validation of the new TNM classification for lung cancer performed by independent groups is generally partial: not all changes can be replicated in every series. In their own series, they did not find significant differences between the survival rates of patients with pathologic (p) T1bN0M0 tumours and those with pT2aN0M0 tumours, nor between those with pT4N0M0 and pT3N0M0 tumours. However, they could replicate the prognostic significance of subdividing pT2 into pT2a and pT2b, and that of the new pT3 category. Furthermore, the survival deterioration that occurs with increasing pathologic stage was more clearly seen when tumour stage was classified according to the 7th edition, although a low concordance index indicated no differences in the prediction of survival of both classifications.

These discrepancies in the results of the analyses of different series are normal because the populations are different from that of the IASLC database. Both the strength and the weakness of the IASLC database reside in its vastness. On the one hand, a large number of patients with lung cancer, treated with all available therapies, was collected internationally from different local databases, thus providing wide geographic representation, and large number of patients with detailed data on the TNM descriptors. On the other hand, many of the contributing databases had not been designed to validate the TNM classification and lacked the information on the TNM descriptors that was required to validate them. Regarding the $\mathrm{T}$ component of the classification, the IASLC database allowed the detailed analysis of tumour size, additional tumour nodules in the same lobe or in another ipsilateral lobe, and pleural dissemination (malignant pleural effusion and separated pleural nodules). The remaining T2 descriptors (partial atelectasis, visceral pleural invasion and endobronchial location), T3 descriptors (total atelectasis, endobronchial location and the different involved sites) and T4 descriptors (all involved sites, except for additional nodules in the lobe of the primary tumour) could not be evaluated because of the small number of patients in each subgroup, inconsistent clinical and pathologic results, or lack of validation [16]. The IASLC database also allowed the validation of the $\mathrm{N}$ descriptors, clinically and pathologically; but the impact of nodal tumour burden according to the number of nodal zones involved, a relevant finding in clinical practice, could not be validated by geographic area, type of database or $\mathrm{T}$ category. Therefore, it could not be proposed as a change in the new TNM classification [17]. For the M component, there was enough evidence to reclassify pleural dissemination as metastatic disease (M1a), together with contralateral lung 
nodules, but differentiating them from distant metastases (M1b). The database did not allow differentiating between single and multiple nodules in the contralateral lung or between single and multiple metastases, or the prognostic impact of single or multiple metastases in different anatomic sites [18]. In any case, all the changes in the 7th edition of the TNM classification were both internally and externally validated [19] and are the result of the analyses of the largest database ever collected for the purpose of updating and validating the TNM classification for lung cancer. Its international nature and the large number of patients of the IASLC database should ensure that the findings derived from its analyses could be applied in most settings. However, the IASLC database is unique and cannot be compared with single-institution or population-based series. Discrepancies such as those reported by STRAND et al. [1] are to be anticipated when different and smaller populations are analysed. However, this does not decrease the value of the TNM classification, but points out the complexity of tumour classification in general. For specific populations, when the changes in the new classification do not fit, prognosis should be based more on local findings, because they are more likely to represent the reality of each medical setting.

STRAND et al. [1] also elaborate on the fact that the new TNM classification may imply a potential change in treatment indications because of stage migration. In their series, at least theoretically, $17 \%$ of their patients would be candidates for a different treatment compared with that assigned to them by the previous edition of the classification. This change is especially relevant in those patients with T2bN0M0 tumours, now upstaged from stage IB to stage IIA; and those with T2 tumours $>7 \mathrm{~cm}$, that are now reclassified as T3 and, if there is no nodal or metastatic involvement, are in stage IIB. These tumours are now in stages for which adjuvant chemotherapy has proved to impact prognosis, but were not included in the clinical trials that have provided evidence for this therapy. What should we do now? That is the question we all have in mind. Treatment indications should be derived from properly designed clinical trials and new trials will have to be conducted to find out whether adjuvant chemotherapy also plays a role in the TNM subsets that have migrated. In the meanwhile, in daily clinical practice, it is the responsibility of the multidisciplinary team to decide whether adjuvant treatment should be administered or not, based on the tumour characteristics and the patients' postoperative condition.

The TNM classification assesses the anatomic tumour extent only and, among other objectives, it is used to venture a prognosis. Although it is a good prognosticator, it is an imperfect one, because it does not consider the various patient, tumour and environmental factors that influence prognosis. Some of these nonanatomic factors are being progressively combined with anatomic ones to stage other tumours, e.g. age in papillary and follicular thyroid cancer, and mitotic rate in gastrointestinal stromal tumours [20]. Sooner or later, this will be the case for lung cancer; however, until that moment arrives, it is imperative that we collect, analyse and share data, as STRAND et al. [1] have done, to better understand the limitations of the TNM classification and overcome them. The prospective phase of the IASLC Lung Cancer Staging Project is trying to do so with international collaboration, and counts on the sharing of data from around the world to revise and improve the next edition of TNM classification for lung cancer [21].

\section{STATEMENT OF INTEREST}

None declared.

\section{REFERENCES}

1 Strand TE, Rostad H, Wentzel-Larsen T, et al. A population-based evaluation of the seventh edition of the TNM system for lung cancer. Eur Respir J 2010; 36: 401-407.

2 Sobin LH, Wittekind C, eds. TNM Classification of Malignant Tumours. 6th Edn. New York, Wiley-Liss, 2002; pp. 99-103.

3 Goldstraw P, ed. Staging Manual in Thoracic Oncology. Orange Park, Editorial Rx Press, 2009; pp. 56-62.

4 Goldstraw P, Crowley JJ. The International Association for the Study of Lung Cancer international staging project on lung cancer. J Thorac Oncol 2006; 1: 281-286.

5 Zell JA, Ou SHI, Ziogas A, et al. Validation of the proposed International Association for the Study of Lung Cancer non-small cell lung cancer staging system revisions for advanced bronchioloalveolar carcinoma using data from the California Cancer Registry. J Thorac Oncol 2007; 2: 1078-1085.

6 Ou SHI, Zell JA. The applicability of the proposed IASLC staging revisions to small cell lung cancer (SCLC) with comparison to the current UICC 6th TNM edition. J Thorac Oncol 2009; 4: 300-310.

7 Ou SHI, Zell JA. Validation study of the proposed IASLC staging revisions of the $\mathrm{T} 4$ and $\mathrm{M}$ non-small cell lung cancer descriptors using data from 23,583 patients in the California Cancer Registry. J Thorac Oncol 2008; 3: 216-227.

8 Oliaro A, Filosso PL, Cavallo A, et al. The significance of intrapulmonary metastasis in non-small cell lung cancer: upstaging or downstaging? A re-appraisal for the next TNM staging system. Eur J Cardiothorac Surg 2008; 34: 438-443.

9 Lee JG, Lee CY, Kim DJ, et al. Non-small cell lung cancer with ipsilateral pulmonary metastases: prognosis analysis and staging assessment. Eur J Cardiothorac Surg 2008; 33: 480-484.

10 Filosso PL, Ruffini E, Pizzato E, et al. Multifocal (MF) T4 non-small cell lung cancer: a subset with favourable prognosis. Interac Cardiovasc Thorac Surg 2008; 7: Suppl. 3, 227.

11 Lee JG, Lee CY, Bae MK, et al. Validity of the International Association for the Study of Lung Cancer proposals for the revision of N descriptors in lung cancer. J Thorac Oncol 2008; 3: 1421-1426.

12 Fukui T, Mori S, Hatooka S, et al. Prognostic evaluation based on a new TNM staging system proposed by the International Association for the Study of Lung Cancer for resected nonsmall cell lung cancers. J Thorac Cardiovasc Surg 2008; 136: 1343-1348.

13 Suzuki M, Yoshida S, Tamura H, et al. Applicability of the revised International Association for the Study of Lung Cancer staging system to operable non-small-cell lung cancers. Eur J Cardiothorac Surg 2009; 36: 1031-1036.

14 Ruffini E, Filosso PL, Bruna MC, et al. Recommended changes for $\mathrm{T}$ and $\mathrm{N}$ descriptors proposed by the International Association for the Study of Lung Cancer - Lung Cancer Staging Project: a validation study from a single-centre experience. Eur J Cardiothorac Surg 2009; 36: 1037-1044.

15 Yano $\mathrm{T}$, Morodomi $\mathrm{Y}$, Ito $\mathrm{K}$, et al. Verification of the newly proposed $\mathrm{T}$ category (seventh edition of the tumor, node metastasis classification) from a clinicopathological viewpoint in non-small cell lung cancer - Special reference to tumor size. J Thorac Oncol 2010; 5: 45-48.

16 Rami-Porta R, Ball D, Crowley J, et al. The IASLC lung cancer staging project: proposals for the revision of the $\mathrm{T}$ descriptors in 
the forthcoming (seventh) edition of the TNM classification for lung cancer. J Thorac Oncol 2007; 2: 593-602.

17 Rusch VW, Crowley J, Giroux DJ, et al. The IASLC lung cancer staging project: proposals for the revision of the $\mathrm{N}$ descriptors in the forthcoming seventh edition of the TNM classification for lung cancer. J Thorac Oncol 2007; 2: 603-612.

18 Postmus PE, Brambilla E, Chansky K, et al. The IASLC lung cancer staging project: proposals for revision of the $\mathrm{M}$ descriptors in the forthcoming (seventh) edition of the TNM classification of lung cancer. J Thorac Oncol 2007; 2: 686-693.
19 Groome PA, Bolejack V, Crowley JJ, et al. The IASLC lung cancer staging project: validation of the proposals for revision of the $\mathrm{T}, \mathrm{N}$, and $\mathrm{M}$ descriptors and consequent stage groupings in the forthcoming (seventh) edition of the TNM classification of malignant tumours. J Thorac Oncol 2007; 2: 694-705.

20 Sobin LH, Gospodarowicz MK, Wittekind C, eds. TNM Classification of Malignant Tumours. 7th Edn. Oxford, Wiley-Blackwell, 2010.

21 Giroux DJ, Rami-Porta R, Chansky K, et al. The IASLC lung cancer staging project: data elements for the prospective project. J Thorac Oncol 2009; 4: 679-683. 